
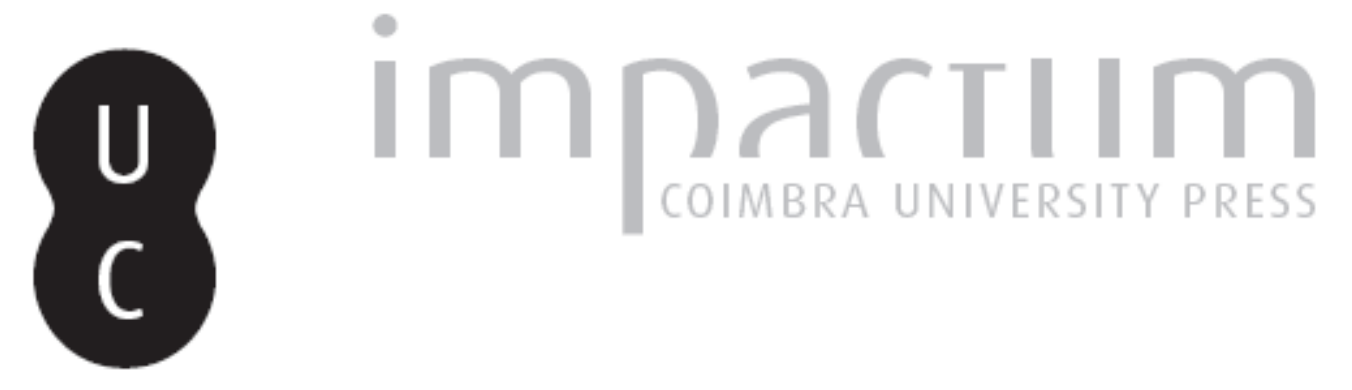

\title{
Petrarca na voz portuguesa de Vasco Graça Moura
}

Autor(es): Dasilva, Xosé Manuel

Publicado por: Imprensa da Universidade de Coimbra

URL persistente:

URI:http://hdl.handle.net/10316.2/42680

DOI:

DOl:https://doi.org/10.14195/0870-8584_1_3

Accessed : $\quad$ 26-Apr-2023 11:46:40

A navegação consulta e descarregamento dos títulos inseridos nas Bibliotecas Digitais UC Digitalis, UC Pombalina e UC Impactum, pressupõem a aceitação plena e sem reservas dos Termos e Condições de Uso destas Bibliotecas Digitais, disponíveis em https://digitalis.uc.pt/pt-pt/termos.

Conforme exposto nos referidos Termos e Condições de Uso, o descarregamento de títulos de acesso restrito requer uma licença válida de autorização devendo o utilizador aceder ao(s) documento(s) a partir de um endereço de IP da instituição detentora da supramencionada licença.

Ao utilizador é apenas permitido o descarregamento para uso pessoal, pelo que o emprego do(s) título(s) descarregado(s) para outro fim, designadamente comercial, carece de autorização do respetivo autor ou editor da obra.

Na medida em que todas as obras da UC Digitalis se encontram protegidas pelo Código do Direito de Autor e Direitos Conexos e demais legislação aplicável, toda a cópia, parcial ou total, deste documento, nos casos em que é legalmente admitida, deverá conter ou fazer-se acompanhar por este aviso.

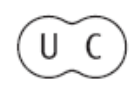




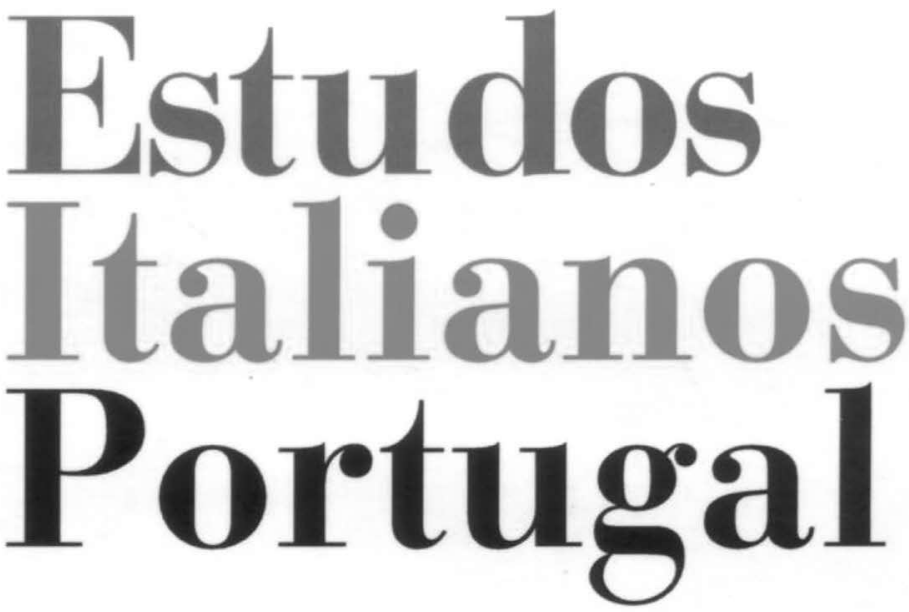

Instituto

Italiano

de Cultura

em Portugal

Nova Série

$\mathbf{N}^{\circ} \mathbf{1}$

2006 
PETRARCA NA VOZ PORTUGUESA

DE VASCO GRAÇA MOURA*

Xosé Manuel Dasilva

No PASSADO ANO DE 2004, as comemorações do sétimo centenário do nascimento de Petrarca serviram, além do mais, para preencher uma lacuna no património cultural português. Com efeito, a língua de Camões não tinha até agora uma edição completa da obra petrarquesca escrita em italiano, composta, designadamente, pelo Canzoniere e pelos Triumphi. Em plena fase de recuperação de textos fundamentais das letras clássicas, através de diversas traduções para português, Vasco Graça Moura achou por bem acabar com essa situação de penúria no atinente ao poeta toscano, e no breve prazo de apenas uns meses deu ao prelo duas versões das mencionadas obras ${ }^{1}$.

Primeiro que tudo, é interessante chamar a atenção, de modo especial, para a dedicação de Graça Moura ao exercício de verter textos de outras línguas, já que não representa, no conjunto da sua produção tão plural, uma actividade de categoria inferior ou de transcendência acessória. Há que lembrar que um dos reconhecimentos mais importantes que o autor de $A$ Sombra das Figuras recebeu, o Prémio Pessoa, foi atribuído ao seu esforço como tradutor de Dante. Este

* Agradeço a revisão do texto a Rúben C. Nunes Duarte.

Vasco Graça Moura, As Rimas de Petrarca, Lisboa, Bertrand, 2003; Vasco Graça Moura, Os Triunfos de Petrarca, Lisboa, Bertrand, 2004. 
facto não deve deixar de ser frisado, pois pode existir a tentação de pensar na natureza secundária da faceta de Graça Moura como tradutor, sobretudo tendo em vista a sua vastíssima produtividade neste campo, bem ilustrada, aliás, no caso de Petrarca. É merecedora de elogio, realmente, uma tarefa como a que consistiu em trasladar, com bons resultados, a obra do escritor de Arezzo, tendo em conta o período cronológico muito reduzido necessário para tal tarefa.

A chave do sucesso foi, no início, aquilo que o próprio Graça Moura qualificou como uma questão de método, isto é, de destreza para se organizar. Quanto às Rimas, essa capacidade resumiu-se, por exemplo, na tradução ou de cinco sonetos, ou de uma canção por noite, e, para os Triunfos, a diligência terá sido sensivelmente a mesma. Nulla dies sine linea, portanto, foi um princípio basilar no labor translatório de Graça Moura. Apenas a constância, todavia, não explica a decisão de ter adoptado um ritmo de trabalho tão disciplinado e, além disso, tão vertiginoso. Houve, com certeza, uma outra motivação mais poderosa e menos trivial na preferência por um tal método. O tradutor compreendeu que o valor do método se apoiava, mormente, em manter um leque de mecanismos em tensão que lhe permitissem transportar, sem dissonâncias - numa entrega, por conseguinte, dotada de unidade -, o canto original de Petrarca, de feitio magnificente em tantos planos da expressão verbal ${ }^{2}$. Fixado de antemão o programa de tradução, e de acordo com o método descrito, Graça Moura pôs em português o Canzoniere. Em seguida, sob o mesmo "impulso"3 - ou com a mão na massa, segundo outras palavras mais coloquiais do próprio tradutor - viu-se culminado o empreendimento com os Triumphi.

\footnotetext{
2 Mário Santos, "Petrarca segundo Graça Moura", Público, 1-11-2003.
}

3 Vasco Graça Moura, "Os Triunfi de Petrarca", em Os Triunfos de Petrarca, Lisboa, Bertrand, 2004, p. 11.
Para confirmarmos o peso da prática tradutora em Graça Moura, cumpre reparar que foram objecto do seu apreço, com o intuito de os verter para a língua portuguesa, Ronsard, Villon, Rilke, Shakespeare e Dante, entre outros mais. Mas porquê agora Petrarca, quando a trajectória literária do autor de Antologia dos Sessenta Anos é já mais comprida do que curta? Houve quem opinasse, e de forma criteriosa, que Petrarca constitui, até certo ponto, uma agradável novidade no mosaico canónico que Graça Moura tem construído com os autores que traduziu, levando em conta, nomeadamente, uma alusão displicente ao cantor de Laura como a que aparece no poema "O Desgaste das Imagens", de A Furiosa Paixão pelo Tangível (1987) ${ }^{4}$. Esclareça-se, a propósito disso, que as traduções petrarquescas de Graça Moura não tiveram origem em qualquer encomenda de tipo editorial, de modo que a influência da data comemorada por ocasião do centenário do grande escritor terá sido, nesta escolha, de realce limitado. Qual, então, a motivação para as versões do Canzoniere e dos Triumphi? Porventura a aceitação definitiva, por parte de Graça Moura, da influência marcante que Petrarca foi capaz de exercer em toda a cultura ocidental e, em particular, na história literária portuguesa.

É pertinente recordar que Graça Moura costuma conceber o acto de transpor um dado autor como uma oportunidade favorável para aprofundar a obra desse mesmo criador. Poder-se-ia dizer que a tradução é contemplada como via de percepção intelectual, e, assim sendo, também como acção de dimensões metaliterárias. Isto evidencia que Petrarca é, hoje em dia, com direito natural, mais uma peça

${ }^{4}$ Fernando J. B. Martinho, "Petrarca na Poesia Portuguesa Contemporânea”, Petrarca 700 anos, coordenação de Rita Marnoto, Coimbra, Instituto de Estudos Italianos da Faculdade de Letras da Universidade de Coimbra, 2005, p. 77. 
no mosaico de nomes predilectos de Graça Moura. Com a decisão de o traduzir, o escritor português estaria mostrando, ao mesmo tempo, uma resoluta vontade de conhecer o poeta italiano de maneira mais arraigada. É sabido que, através da obra de Graça Moura, a presença do alheio adquire, não raro, carácter essencial na qualidade de recurso artístico, mais ainda quando estão em jogo referências de teor clássico ${ }^{5}$.

Para lá desse motivo que teria conduzido Graça Moura a traduzir Petrarca, há uma outra causa não menos importante, porém, que está na base das suas versões. Como antes ficou dito, Portugal carecia de uma tradução integral do Canzoniere e dos Triumphi, o que era uma anomalia só surpreendente em alguma medida. De um percurso superficial através da recepção ibérica da obra em vulgar de Petrarca logo resulta a emergência de tal ideia ${ }^{6}$.

Em língua espanhola, a primeira tradução conhecida dos Triumphi, feita por Antonio de Obregón, foi publicada em 1512, e é uma adaptação em quintilhas heptassilábicas, de acordo com os modelos então imperantes em solo peninsular ${ }^{7}$. Em metro idêntico surgiria a tradução seguinte, de Álvar Gómez de Ciudad Real ${ }^{8}$, a situar em data anterior a

${ }^{5}$ Isabel Pires de Lima, "Entre dois mundos: referências clássicas na poesia de Graça Moura”, Camões, 2, 1998, pp. 109-116.

${ }^{6}$ Vd. José María Micó, "La época del Renacimiento y del Barroco", em Francisco Lafarga \& Luis Pegenaute, eds., Historia de la Traducción en España, Salamanca, Editorial Ambos Mundos, 2004, pp. 175-208; José Francisco Ruiz Casanova, Aproximación a una historia de la traducción en España, Madrid, Cátedra, 2000, pp. 173-175; Esperanza Seco, "Historia de las traducciones literarias del italiano al español durante el Siglo de Oro (Influencias)", Cuadernos para la Investigación de la Literatura Hispánica, 13, 1990, pp. 41-97.

Vd. A. J. Cruz, "Los Trionfi en España: la poética petrarquista, la teoría de la traducción y la lengua vernácula en el siglo XVI", Anuario de Estudios Medievales, 25, 1995, pp. 307-324; Roxana Recio, "Traductor y traducción: Los Triunfos de la Muerte de Obregón y Coloma”, Livius, 3, 1993, pp. 229-240.

8 El "Triunpho de amor" de Petrarca traduzido por Álvar Gómez de Ciudad Real, Barcelona, PPU, 1998. Edición crítica, introducción y notas de Roxana Recio. Vd.
1538. Para além de uma outra versão de Juan de Coloma ${ }^{9}$, somente a tradução de Hernando de Hozes, em meados do século, respeitaria a forma métrica original, utilizando o verso dacassilábico. Este tradutor estava já consciente da revolução que as novidades introduzidas por Boscán e Garcilaso tinham significado para a poesia ibérica, como se pode verificar com clareza no prólogo desta versão.

Rita Marnoto indicou, com muita pertinência, que o elevado número de exemplares de traduções espanholas em bibliotecas lusas revela que, na altura, muitos leitores portugueses as utilizavam para se aproximarem dos Triumphi $i^{10}$. Contudo, e com independência de algumas notícias avulsas sobre outras possíveis traduções, torna-se factível registar, como a mesma estudiosa aponta ${ }^{11}$, a existência de uma versão em língua portuguesa desta obra petrarquesca. Ela aparece num manuscrito guardado na Biblioteca e Arquivo

Carlos Alvar, "Álvar Gómez de Guadalajara y la traducción del Trionfo d'amore", em Juan Paredes, ed., Medioevo y literatura. Actas del IV Congreso de la Asociación Hispánica de Literatura Medieval, Granada, Universidad de Granada, 1995, pp. 261-267; J. María Azaceta, "Petrarca traducido por Álvar Gómez. Nuevos datos para el estudio del influjo del poeta italiano en nuestra lírica renacentista", em El Cancionero de Gallardo, Madrid, CSIC, 1962, pp. 42-48; Roxana Recio, La traducción del "Triunfo de amor" de Petrarca por Alvar Gómez de Ciudad Real: un estudio sobre la poesía de cancionero y sobre las teorías medievales y renacentistas de la traducción, Ann Arbor, 1993; Roxana Recio, Petrarca y Alvar Gómez: la traducción del "Triunfo de amor", New York, Peter Lang, 1996; Roxana Recio, "Las canciones intercaladas en la traducción del Triunfo de Amor de Petrarca por Álvar Gómez de Ciudad Real”, Hispanic Journal, 12, 1991, pp. 247-265; Giuseppe Carlo Rossi, "Una traduzione cinquecenta spagnola del Trionfo d'Amore", Convivium, V, 1959, pp. 40-50.

9 María del Pilar Manero Sorolla, "Triunfo de la muerte de Petrarca traducido por Juan de Coloma”, Anuario de Estudios Medievales, 23, 1993, pp. 563-578.

${ }^{10}$ Rita Marnoto, O Petrarquismo Português do Renascimento e do Maneirismo, Coimbra, Universidade de Coimbra, 1997, p. 27.

11 Marnoto, O Petrarquismo Português, pp. 345-347. 
Distrital de Évora ${ }^{12}$, e trata-se de uma tradução incompleta recuperada no século XIX pelo Visconde de Juromenha, que a incluiu, sem fundamento lógico, na sua edição da obra lírica de Camões.

Quanto ao Canzoniere, as versões peninsulares mais primitivas foram feitas em espanhol, também no século XVI, por El Brocense, que trasladou 11 sonetos, e por Salomón Usque, hebreu de origem portuguesa, que publicou, no ano de 1567, em Veneza, a tradução da Primeira Parte ${ }^{13}$. A primeira tradução completa do Canzoniere para uma língua ibérica pertence a Henrique Garcês, nascido também em Portugal, terceiro tradutor espanhol de Os Lusíadas após Bento Caldeira e Luis Gómez de Tapia, que dá à luz em Madrid, no ano de 1591, Los sonetos y canciones del Poeta Francisco Petrarcha ${ }^{14}$. Na verdade, não se tem notícia de qualquer tradução do Canzoniere realizada em Portugal.

12 Vd. Giacinto Manupella, Uma anónima versão quinhentista dos Triunfos de Petrarca e o seu comentário, Coimbra, 1974.

13 Vd. María del Pilar Manero Sorolla, "La primera traducción de las Rime de Petrarca en lengua castellana: Los sonetos, canciones, mandriales y sextinas del gran poeta y orador Francisco Petrarca de Salomon Usque", em Adolfo Sotelo, coord., \& María Cristina Carbonell, ed., Homenaje al profesor Antonio Vilanova, I, Barcelona, Universidad de Barcelona, 1989, pp. 377-391; Franco Meregalli, "Sulle prime traduzioni spagnole di sonetti del Petrarca", em Traduzione e tradizione europea del Petrarca. Atti del III Convegno sui problemi della traduzione letteraria, Padova, Antenore, 1975, pp. 55-63; Víctor Eduardo Krebs Bermúdez, "Las traducciones de un soneto de Petrarca en el Renacimiento español", em Roxana Recio, ed., La traducción en España. Siglos XIV-XVI, León, Universidad de León, 1995, pp. 191-220.

${ }^{14}$ Vd. Dámaso Alonso, "La recepción de Os Lusíadas en España", Obras Completas, vol. III, Madrid, Editorial Gredos, 1974, pp. 9-40; uma primeira versão, sob o mesmo título, foi publicada em Boletín de la Real Academia Española, LIII, 1973, pp. 33-61; Eugenio Asensio, La fortuna de Os Lusíadas en España (1572-1672), Madrid, Fundación Universitaria Española, 1973; depois publicado em Estudios portugueses, Paris, Fundação Calouste Gulbenkian, Centro Cultural Português, 1973, pp. 303-324; Sousa Viterbo, "Henrique Garcês, tradutor d'Os Lusíadas em Espanhol”, Círculo Camoniano, 1, 1891, pp. 316-323.
Este panorama das versões ibéricas da obra italiana de Petrarca, desenhado aqui só a traços largos, leva a confirmar que a tentativa de Graça Moura possui, mesmo no século XXI, uma significação histórica incontestável. Foi necessário esperar setecentos anos, o que não é pouco tempo, para termos em idioma português uma tradução total do Canzoniere e dos Triumphi.

É de interesse analisar, ainda, os critérios que nortearam as traduções petrarquescas de Graça Moura. Embora fragmentárias, há algumas reflexões suas quanto ao fenómeno tradutor que podem ser úteis. Por exemplo, Graça Moura opinou que a translação de textos poéticos é, mais do que uma operação maquinal, um repto aliciante em que prevalece a necessidade de transplantar aquilo que determina a diferença estética - o semelhante depende sempre do óbvio - entre o texto original e o texto traduzido. O objectivo não é obter uma reprodução sem substância própria, mas um produto que seja efectivo, em termos estéticos, para o novo receptor. Torna-se oportuno trazer à baila aquela consideração de Graça Moura a respeito de a infidelidade ser, amiúde, o melhor caminho para atingir, na transferência do género poético, a fidelidade mais rigorosa ${ }^{15}$

Esta percepção do que é a tradução poética lembra o que Octávio Paz, para quem, por sinal, traduzir e criar eram operações gémeas, expunha a propósito das composições admiráveis - e tão alheias quanto próprias - do seu volume Versiones $y$ diversiones. O poeta mexicano dizia que, a partir de poemas noutras línguas, tinha procurado fazer poemas na sua língua. Não é o momento de nos internarmos no conflituoso debate sobre a conveniência de estar na condição de mestre da escrita para trasladar poesia. Sem espaço para argumentações e réplicas acerca de um assunto tão espinhoso,

15 Vasco Graça Moura, "João Barrento e o poço de Babel”, Os Meus Livros, 9, 2003, pp. 66-67. 
diga-se aqui apenas que é aconselhável, ao traduzir literatura poética, exibir ofício artístico. E quem costuma, de maneira consensual, estar na posse da arte de escrever é - ao menos por definição - o escritor.

No que concerne à estratégia que presidiu a estas versões petrarquescas de Graça Moura, há que fazer sobressair, principalmente, a supremacia da forma dos textos de partida. Preponderou, com efeito, a conservação das características métricas dos poemas, como a medida, a rima e o ritmo. É uma opção bem legítima a fim de alcançar, na língua para que se traduz, um fiel reflexo do original correspondente, sem incorrer, por isso, na mera literalidade. Tal premissa cumpriu-se no caso de todos os géneros que fazem parte do Canzoniere, do soneto à sextina, incluindo as canções, as baladas e os madrigais, e está também patente no caso da terza rima dos Triumphi.

Ou seja, pode-se dizer que, tanto quanto possível, Graça Moura decalcou - na acepção mais conscienciosa do vocábulo - a aparência das composições de Petrarca, o que implica uma alta dose de habilidade artesanal por parte do tradutor. Uma tal atitude não teve como contrapartida, porém, a marginalização dos ingredientes conceptuais que o aprimorado discurso dos versos petrarquescos desvenda, o que denota, por sua vez, uma elevada capacidade criadora.

O mérito primordial foi atingir um ponto de equilíbrio entre configuração externa e elementos significativos, sem que um desses dois aspectos fosse privilegiado mais do que outro. Esse mérito só se consegue graças a um trabalho paciente de negociação poética, renunciando cá e ganhando lá, umas vezes sacrificando matizes e outras vezes compensando essas perdas. Há que evitar o risco de converter o poema traduzido apenas numa glosa vulgar do poema original, como resultado de a versão se submeter, de modo absoluto, à tirania dos constituintes métricos em prejuízo dos componentes semânticos.
Em conclusão, a obra de Petrarca em italiano fica, a partir destas versões do Canzoniere e dos Triumphi de Graça Moura, ao dispor dos leitores portugueses na sua própria língua. O balanço é digno de ser destacado e, falando em textos petrarquescos, talvez nada haja mais adequado do que evocar aquele louvor que diz respeito a dois ilustres petrarquistas, Garcilaso de la Vega e Juan de Boscán. Na dedicatória do tratado a D. Gerónima Palova de Almogávar, o primeiro exaltava assim o merecimento do segundo, como tradutor de Il Cortigiano de Baltasar de Castiglione:

Y supo vuestra merced muy bien escoger persona por cuyo medio hiciésedes este bien a todos, que siendo a mi parecer tan dificultosa cosa traducir bien un libro como hacerle de nuevo, dióse Boscán en esto tan buena maña, que cada vez que me pongo a leer este su libro o (por mejor decir) vuestro, no me parece que le hay escrito en otra lengua. Y si alguna vez me acuerda del que he visto y leído, luego el pensamiento se me vuelve al que tengo entre las manos. 